\title{
Análise fitoquímica preliminar das folhas de Vitex Megapotamica (Sprengel) Moldenke
}

\author{
Thiele Faccim de Brum*, Marina Zadra**, Amanda Luana Forbrig \\ Froeder**, Aline Augusti Boligon*, Janaína Kieling Frohlich*, \\ Margareth Linde Athayde*
}

RESUMO: A espécie Vitex megapotamica (Sprengel) Moldenke, usualmente conhecida como tarumã, pertence à família Verbenaceae a qual compreende cerca de 100 gêneros distribuídos nas regiões tropicais de todo o mundo. Esta espécie tem sido usada na medicina tradicional principalmente para hemorróidas, depurativa do sangue, hipertensão arterial, anti-inflamatória, dentre outras. 0 presente trabalho teve por objetivo a realização da triagem farmacognóstica de extratos das folhas de Vitex megapotamica. Os resultados da análise fitoquímica indicaram a presença de heterosídeos antociânicos, fenóis e taninos, catequinas, flavonóis, flavanonas, flavanonóis e xantonas, esteroides e triterpenoides (esteroides livres), heterosídeos cardioativos, fenóis com posição orto e meta livres, fenóis com a posição para livre, cumarinas, ácidos orgânicos e fenóis.

Descritores: Vitex megapotamica; Tarumã; Folhas; Estudo fitoquímico.

\section{Phytochemical preliminary analysis leaves of Vitex Megapotamica (Sprengel) Moldenke}

ABSTRACT: The species Vitex megapotamica (Sprengel) Moldenke, usually known as tarumã, belongs to the Verbenaceae family which comprises about 100 genera distributed in tropical regions around the world. This species has been mainly used in traditional medicine for hemorrhoids, purifying the blood, hypertension, anti-inflammatory, and others. The aim of this study was to carry out a pharmacognostic screening of extracts of $V$. megapotamica leaves. The results of phytochemical analysis indicated the presence of anthocyanins, phenols and tannins, catechins, flavonols, flavanones, and flavanonóis xanthones, triterpenoids and steroids (steroid free), cardioactive glycosides, phenols with ortho and meta position free phenol with the position free, coumarins, organic acids and phenols.

Descriptors: Vitex megapotamica; Tarumã; Leaves; Phytochemical study.

\footnotetext{
* Mestranda em Ciências Farmacêuticas pela Universidade Federal de Santa Maria, Santa Maria, RS, Brasil.

** Graduanda no Curso de Graduação em Farmácia, Universidade Federal de Santa Maria, Santa Maria, RS, Brazil.
} 


\section{Introdução}

Nos últimos anos, tem-se verificado um grande avanço científico, envolvendo os estudos químicos e farmacológicos de plantas medicinais que visam obter novos compostos com propriedades terapêuticas. $^{1}$

Estes produtos naturais podem ser tão eficientes quanto os produzidos pela síntese química, contudo a transformação de uma matéria-prima vegetal em um medicamento deve visar à preservação da integridade química e farmacológica do vegetal, garantindo a constância de sua ação biológica e a sua segurança de utilização, além de valorizar seu potencial terapêutico. Para garantir esses objetivos, a produção de fitoterápicos requer, necessariamente, estudos prévios relativos a aspectos botânicos, agronômicos, fitoquímicos, farmacológicos, toxicológicos, de desenvolvimento de metodologias analíticas e tecnológicas. ${ }^{2}$

Entre as inúmeras espécies vegetais de interesse medicinal, encontra-se a Vitex megapotamica (Sprengel) Moldenke, usualmente conhecida como tarumã, pertence à família Verbenaceae a qual compreende cerca de 100 gêneros distribuídos nas regiões tropicais de todo o mundo. ${ }^{3} \mathrm{~V}$. megapotamica distribui-se no nordeste da Argentina, no leste do Paraguai, no Uruguai e comumente encontrada no sul do Brasil. Na medicina popular, a infusão das folhas desta planta é utilizada no tratamento das hemorróidas, depurativa do sangue (hipocolesterolêmica), diuréticas, afecções cutâneas, expectorante, hipertensão arterial, antiinflamatória, dentre outras propriedades terapêuticas. ${ }^{4-7}$ Para a espécie em estudo foi relatado 0 isolamento de esteróides e iridóides. ${ }^{8,9} \mathrm{Em} \mathrm{2007,} \mathrm{foi} \mathrm{relatada} \mathrm{a} \mathrm{atividade} \mathrm{hipoglicemiante} \mathrm{das}$ folhas de $V$. megapotamica. ${ }^{10}$ e em 2009, foi demonstrado a ação do extrato bruto hidroalcóolico e decocção das cascas sobre efeito hipolipidêmico e redução dos níveis séricos de colesterol e triacilglicerol. ${ }^{11}$ Estes mesmos autores realizaram um estudo fitoquímico preliminar do extrato bruto das folhas de $V$. megapotamica que revela a presença de taninos, glicosídeos flavonônicos, polifenóis, alcalóides, óleos essências e saponinas. Sendo assim, devido à escassez de estudos que comprovem tais efeitos, este estudo teve como objetivo realizar uma análise farmacognóstica dos extratos de V. megapotamica em diferentes solventes. Além disso, complementar outros estudos através de uma pesquisa preliminar das substâncias presentes nos extratos a fim de verificar a possivel presença de grupos químicos oriundos do metabolismo secundário desta espécie.

\section{Materiais e métodos}

\section{Material botânico}

As folhas e os galhos de V. megapotamica foram coletados em dezembro de 2010, no município de Santa Maria, no estado do Rio Grande do Sul. O material testemunho está depositado no herbário do Departamento de Biologia da UFSM catalogado sob o número de registro SMBD 13.071.

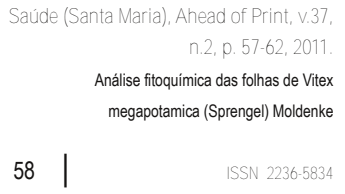




\section{Preparação dos extratos}

As folhas foram secas à temperatura ambiente e posteriormente trituradas em moinho de facas. A seguir, o material (1272,68 $\mathrm{g}$ de pó das folhas) foi submetido à maceração com etanol (70\%) a temperatura ambiente por sete dias com agitação diária. Uma parte do extrato etanólico foi reservada e a outra parte foi filtrada e evaporada para remoção do etanol obtendo-se 0 extrato aquoso remanescente.

\section{Análise fitoquímica}

O extrato aquoso e o extrato etanólico foram submetidos a uma série de reações de caracterização, para o extrato aquoso realizou-se as seguintes reações: heterosídeos antociânicos (cores diferentes pela variação do pH), heterosídeos cianogênicos (reação de ácido sulfúrico e papel picro-sódico), amino-grupos (nebulização com ninhidrina) e ácidos voláteis (variação do pH após fervura); para o extrato hidroalcóolico foram: fenóis e taninos (reação com cloreto férrico), antonianinas, antocianidinas e flavonoides (presença de coloração em pH 3, 8, 5 e 11), leucoantocianidinas, catequinas e flavonas (coloração da amostra alcalinizada e acidificada após aquecimento), flavonóis, flavanonas, flavanonóis e xantonas (reação com magnésio granulado com ácido clorídrico), esteroides e triterpenoides (extração com clorofórmio, anidrido acético e ácido sulfúrico), catequinas (reação com ácido clorídrico e aquecimento), resinas (formação de precipitado através da extração de resíduo sólido com etanol), heterosídeos cardioativos (teste de Kedde e Liebermann-Buchard), fenóis com posição orto e meta livres (reativo de Liebermann), fenóis com a posição para livre (reativo de Millon), cumarinas (extração com éter e câmara de luz ultravioleta), ácidos orgânicos (extração com éter e determinação do pH) e fenóis (reação de precipitação com cloreto férrico), segundo metodologias descritas em publicações especializadas. ${ }^{12,13}$

\section{Resultados e discussão}

A realização da prospecção fitoquímica das folhas de $V$. megapotamica (Tarumã) revelou resultados positivos para a presença de heterosídeos antociânicos, fenóis e taninos, catequinas, flavonóis, flavanonas, flavanonóis e xantonas, esteroides e triterpenoides (esteróides livres), heterosídeos cardioativos, fenóis com posição orto e meta livres, fenóis com a posição para livre, cumarinas, ácidos orgânicos e fenóis. Foram observados testes negativos para heterosídeos cianogênicos, amino-grupos, ácidos voláteis, antonianinas, antocianidinas e flavonoides, leucoantocianidinas e flavonas e resinas (Tabela 1). Os resultados negativos não implicam necessariamente na sua ausência, sendo possível que a quantidade dos mesmos esteja pequena para ser detectada. 
Tabela 1 - Prospecção fitoquímica das folhas de V. megapotamica em dois solventes (aquoso e etanólico); Forte: +++, Médio: ++, Fraco: +, Ausente: O, Não feito: -

Saúde (Santa Maria), Ahead of Print, v.37, n.2, p. 57-62, 2011. Análise fitoquimica das folhas de Vitex megapotamica (Sprengel) Moldenke ISSN 2236-5834

\begin{tabular}{|c|c|c|}
\hline Testes & Aquoso & Hidroalcóolico \\
\hline Heterosídeos antociânicos & +++ & - \\
\hline Heterosídeos cianogênicos & 0 & - \\
\hline Amino-grupos & 0 & - \\
\hline Ácidos voláteis & 0 & - \\
\hline Fenóis e taninos & - & +++ \\
\hline $\begin{array}{l}\text { Antonianinas, antocianidinas e } \\
\text { flavonoides }\end{array}$ & - & 0 \\
\hline $\begin{array}{l}\text { Leucoantocianidinas, catequinas e } \\
\text { flavonas }\end{array}$ & - & $\begin{array}{c}\text { ++ para } \\
\text { catequinas }\end{array}$ \\
\hline $\begin{array}{c}\text { Flavonóis,flavanonas, flavanonóis e } \\
\text { xantonas }\end{array}$ & - & ++ \\
\hline Esteroides e triterpenóides & - & $\begin{array}{l}\text { ++ esteróides } \\
\text { livres }\end{array}$ \\
\hline Catequinas & - & ++ \\
\hline Resinas & - & 0 \\
\hline Heterosídeos cardioativos & - & ++ \\
\hline Fenóis com posição orto e meta livres & - & ++ \\
\hline Fenóis com a posição para livre & - & +++ \\
\hline Cumarinas & - & +++ \\
\hline Ácidos orgânicos & - & ++ \\
\hline Fenóis & - & +++ \\
\hline
\end{tabular}

Os resultados indicam a presença de metabólitos secundários que podem estar relacionados à sua ação no tratamento de diversas patologias. Tendo em vista o resgate da biodiversidade brasileira e identificação das potencialidades das plantas e sua possível ação medicinal, alguns metabólitos secundários são apontados neste estudo como ponto de partida para este enfoque. Conforme a relação dos metabólitos secundários com suas possíveis atividades biológicas descritas por Simões e colaboradores (2010), compostos fenólicos atuam na inibição da peroxidação lipídica e a lipoxigenase, a presença destes pode 
estar relacionados ao uso do tarumã como antiinflamatório e hipolipidêmico, taninos são empregados na medicina tradicional no tratamento de hipertensão arterial, reumatismo, feridas, antioxidante, anti-hemorrágico, cicatrizante, antiulcerogênico e anti-inflamatório em geral. Os heterosídeos cardioativos podem estar relacionados ao uso do tarumã como hipotensor citado na medicina popular. Triterpenos e esteroides atuam como antiinflamatórios e hormonais, as cumarinas como anticoagulante, relaxante vascular, hipolipidêmica e hipotensora. Leucoantocianidinas, flavonas, flavanonas, antocianos, flavonóis conferem propriedades anti-inflamatórias, antivirais, antimicrobiana, antioxidante entre outras. ${ }^{14} \mathrm{~A}$ presença de esteroides e compostos fenólicos encontrados justificam a ação hipolipidêmica já citada para esta espécie. ${ }^{11}$

\section{Conclusão}

A prospecção fitoquímica permitiu a detecção das principais classes de metabólitos secundários desta espécie, possibilitando correlacionar as suas possíveis atividades, com as descritas na literatura. Dessa forma, os farmacógenos encontrados neste estudo acenam para várias possibilidades terapêuticas o que servirá de apoio para direcionar os estudos a fim de se aprofundar ainda mais o conhecimento sobre essa espécie, uma vez que os dados sobre a planta ainda são escassos.

\section{Agradecimentos}

À Bióloga Profa. Dra. Thais Scotti do Canto-Dorow, Departamento de Botânica da Universidade Federal de Santa Maria, por proporcionar a identificação de Vitex megapotamica (SPRENGEL) MOLDENKE.

\section{Referências bibliográficas}

1. Cechinel Filho V, Yunes RA. Estratégias para a obtenção de compostos farmacologicamente ativos a partir de plantas medicinais: conceitos sobre modificação estrutural para otimização da atividade. Quím. Nova 1998; 21(1): p. 99-105.

2. Miguel MD, Miguel GO. Desenvolvimento de fitoterápicos. São Paulo: Robe, 1999.

3. Joly AB. Introdução à taxonomia vegetal. 13ª ed. São Paulo: Companhia Editora Nacional, 2002; p. 579589 .

4. Longhi RA. Árvores e arvoretas do Sul. Porto Alegre: Ed. L\&PM, 1995; p. 151-152.

5. Alice CB, Mentz L, Siqueira NCS, Silva GAAB, Jose KF. Plantas medicinais de uso popular: atlas farmacognóstico. $1^{\text {a }}$ ed. Canoas: Ed. da Ulbra, 1995; p. 185-187.

6. Correa MP. Dicionário das plantas úteis do Brasil e das exóticas cultivadas. Rio de Janeiro: IBDF, 1984.

7. Franco IJ, Fontana VL. Ervas e plantas: a medicina dos simples. Erechim: Imprimax, 1997, p. 177.

Saúde (Santa Maria), Ahead of Print, v.37, n.2, p. 57-62, 2011. Brum, T. F., et al. 
8. Rimpler H. Pterosteron, polypodin B and neues ecdysonartiges steroids (viticosteron E) aus Vitex megapotamica. Tetrahedron Letters, 1969; 5 (10): p. 329-333.

9. Rimpler H. Phytoecdysones and iridoids from Vitex megapotamica. Archiv der Pharmazie 1972; 10 (305): p. 746-751.

10. Zanatta L, Sousa E, Cazarolli LH, Junior AC, Pizzolatti MG, Szpoganicz B, Silva FRMB. Effect of crude extract and fractions from Vitex megapotamica leaves on hyperglycemia in alloxan-diabetic rats. Journal of Ethnopharmacology, 2007, n. 109, p. 151-155.

11. Brandt AP, Oliveira LFS, Fernandes FB, Alba J. Avaliação in vivo do efeito hipocolesterolêmico e toxicológico preliminar do extrato bruto hidroalcoólico e decocção da Vitex megapotamica (Spreng) Moldenke (V. montevidensis Cham.). Rev. Bras. Farmacogn. 2009; 19(2A): p. 388-393.

12. Moreira EA. Contribuição para o estudo fitoquímico de Lobelia hassleri A. ZAHLB e Lobelia stellfeldii R. Braga. Companulaceae. Tribuna Farmacêutica 1979; 47 (1): 13-39.

13. Matos FJA. Introdução à fitoquímica experimental. $3^{\mathrm{a}}$ ed. Fortaleza: Editora da UFC; 2009.

14. Simões CMO, Schenkel EP, Gosmann G, Mello JCP, Mentz LA,Petrovick PR. Farmacognosia: da planta ao medicamento. $6^{\text {a }}$ ed. Porto Alegre/Florianópolis: Editora da UFRGS / Editora UFSC; 2010.

\section{Thiele Faccim de Brum}

Endereço para correspondência: Rua Silva Jardim, 1854, apto 82. — CEP: 97010-490, Santa Maria, RS, Brasil.

E-mail: thi_chaim@yahoo.com.br

Recebido em 30 de maio de 2011.

Aprovado em 13 de setembro de 2011. 